\title{
Peculiarities of the thoracic-lumbar vertebral morphology in common mole, Talpa europaea (Lipotyphla, Talpidae) in connection with its burrowing activity
}

\begin{abstract}
Vladimir V. Platonov
ABSTRACT. Morphology of the thoracic and lumbar vertebrae is described. During digging and moving through the tunnel mole can turn anterior part of its body relative to the posterior part up to $90^{\circ}$. An original method to estimate the rotation angle between two vertebrae was devised. It was revealed that the main twisting range occur in the thorax region, and in the lumbar region it comes to naught. The absence or weak development of the spinous process in the anterior thoracic vertebrae indicate weakness of the musculature responsible for the head raising. Based on this observation it is asserted that mole can not use its head for throwing out the soil.
\end{abstract}

KEY WORDS: Talpa europaea, vertebral column, morphology, burrowing.

VladimirV. Platonov [vladimirplatonov@yahoo.com], Zoological Institute, Russian Academy of Sciences, Universitetskaya nab. 1, Saint Petersburg 199034, Russia.

\section{Особенности строения грудопоясничного отдела позвоночника крота Talpa europaea (Lipotyphla, Talpidae) в связи с роющей деятельностью}

\begin{abstract}
В.В. Платонов
РЕЗЮМЕ. Описана морфология грудных и поясничных позвонков. Во время рытья и движения по туннелю крот может поворачивать переднюю часть тела по отношению к задней на угол до $90^{\circ}$. Для вычисления угла поворота между двумя позвонками была разработана оригинальная методика. Установлено, что основной диапазон скручивания приходится на грудной отдел, а в поясничном отделе скручивание сходит на нет. Отсутствие или слабое развитие остистых отростков передних грудных позвонков указывает на неразвитость мускулатуры, ответственной за поднятие головы. Вследствие этого предполагается, что крот не может выталкивать землю головой.
\end{abstract}

КЛЮЧЕВЫЕ СЛОВА: Talpa europaea, позвоночник, морфология, рытье.

\section{Introduction}

The morphological peculiarities of burrowing mammals are well known for their musculature and extremities skeleton (e.g., Dobson, 1882; Reed, 1951; Gambaryan, 1960). However, the specific adaptive features of the axial skeleton, which is, undoubtedly, influenced by the burrowing mode of life, have been hardly investigated yet. The aim of this paper is to reveal such adaptive features in the thoracic and lumbar regions in common mole, Talpa europaea Linnaeus, 1758. For this purpose the morphology of these vertebrae was investigated and described herein. To elucidate the level of the vertebrae mobility a new method of estimation the rotation angle between the two vertebrae during the axial twisting was proposed. Looking at the thoracic vertebrae anteriorly (Fig. 1A) it could be seen that articulation surfaces of the zygapophyses are not in one plane and slightly rounded. Based on this observation, it was suggested that the sliding articulation surfaces are form- ing a spherical trajectory during the axial twisting. Then the determination of the rotation center could allow to estimate the rotation angle between two vertebrae.

\section{Material and methods}

The vertebral morphology was studied on dry skeletons from the collection of the Zoological Institute, Russian Academy of Sciences, Saint Petersburg. Five skeletons of mole, Talpa europaea, were investigated. The following taxa were used in comparative purposes: Siberian zokor, Myospalax myospalax Laxmann, 1773 (two skeletons), Norway rat, Rattus norvegicus(Berkenhout, 1769) (two skeletons), large Japanese mole, Mogera robusta Nehring, 1891 (five skeletons), eastern American mole, Scalopus aquaticus (Linnaeus, 1758) (two skeletons), and star-nosed mole, Condilura cristata (Linnaeus, 1758) (two skeletons).

To estimate the rotation angle between two vertebrae during the axial twist the following methodic was ap- 


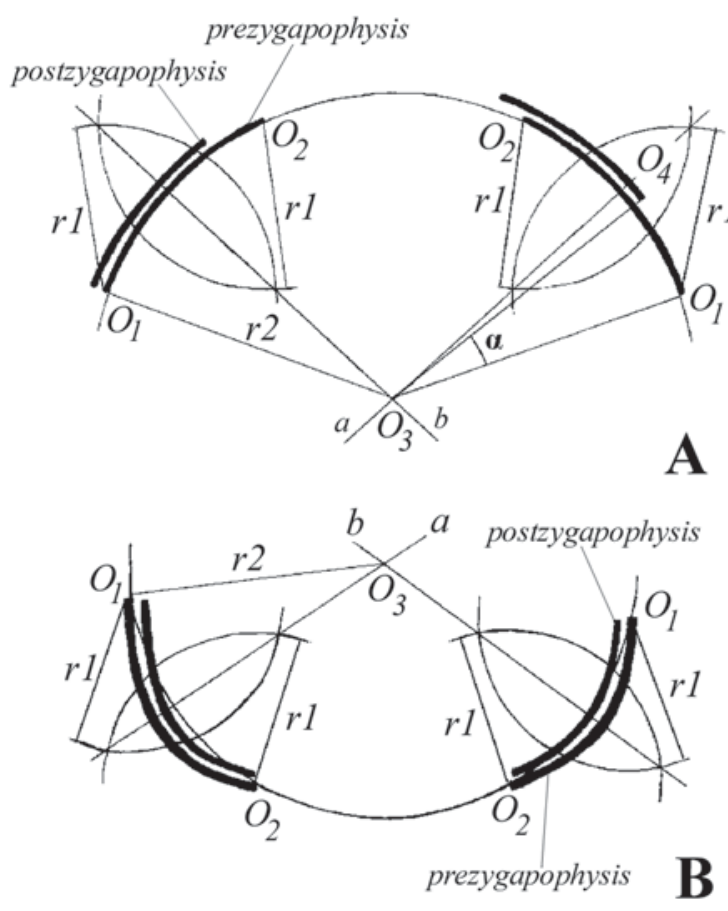

Figure 1. Rotational angle (á) between two adjacent vertebrae. A - postzygapophyses of the third thoracics superimposed on the prezygapophyses of the fourth thoracic (solid arcs). Rotation between the vertebrae is possible; B - postzygapophyses of the third lumbaric superimposed on the prezygapophyses of the fourth lumbaric (solid arcs). Rotation between the vertebrae is not possible. For future explanations see the text.

plied. The schematic frontal section through the postzygapophyses of the third thoracic vertebra and prezygapophyses of the fourth thoracic vertebra is present in Fig. 1A. The articulation zygapophyseal surfaces on this figure are depicted as solid arcs. Using the camera Lucida the postzygapophyseal articulation surfaces were superimposed on the prezygapophyseal articulation surfaces in such a way that the left lateral edges of both surfaces were at the same level. To obtain the rotation center between the two vertebrae the following operations were performed (Fig. 1A). Two circles with a radius $r l$ of arbitrary length (about two thirds of the distance between the points $O 1$ and $O 2$ ) were drew from the points $O 1$ and $O 2$ on both left and right zygapopheses. The crossing points of both left and right circles produced two straight lines ( $a$ and $b$ ), which crossing point would be the supposed rotation center $(O 3)$ between the two vertebrae. Then an arc with the radius $r 2$, equal to the distance $\mathrm{O} 1-\mathrm{O} 3$, was drawn. It is assumed that the rotation between two adjacent vertebrae is existing, if this arc with radius $O 1-O 3$ coincides with the articulation surfaces of the zygapophyses. If such a coincidence does not exist, the rotation is not possible (like in Fig. 1B). An angle aa between the straight lines O3-O4 and $O 3-O 1(\boldsymbol{\alpha})$ (Fig. 1A) would be the maximum displacement of one vertebra relative to another. Half of this angle would be a rotational angle of one vertebra relative to another from the normal (midline) position.

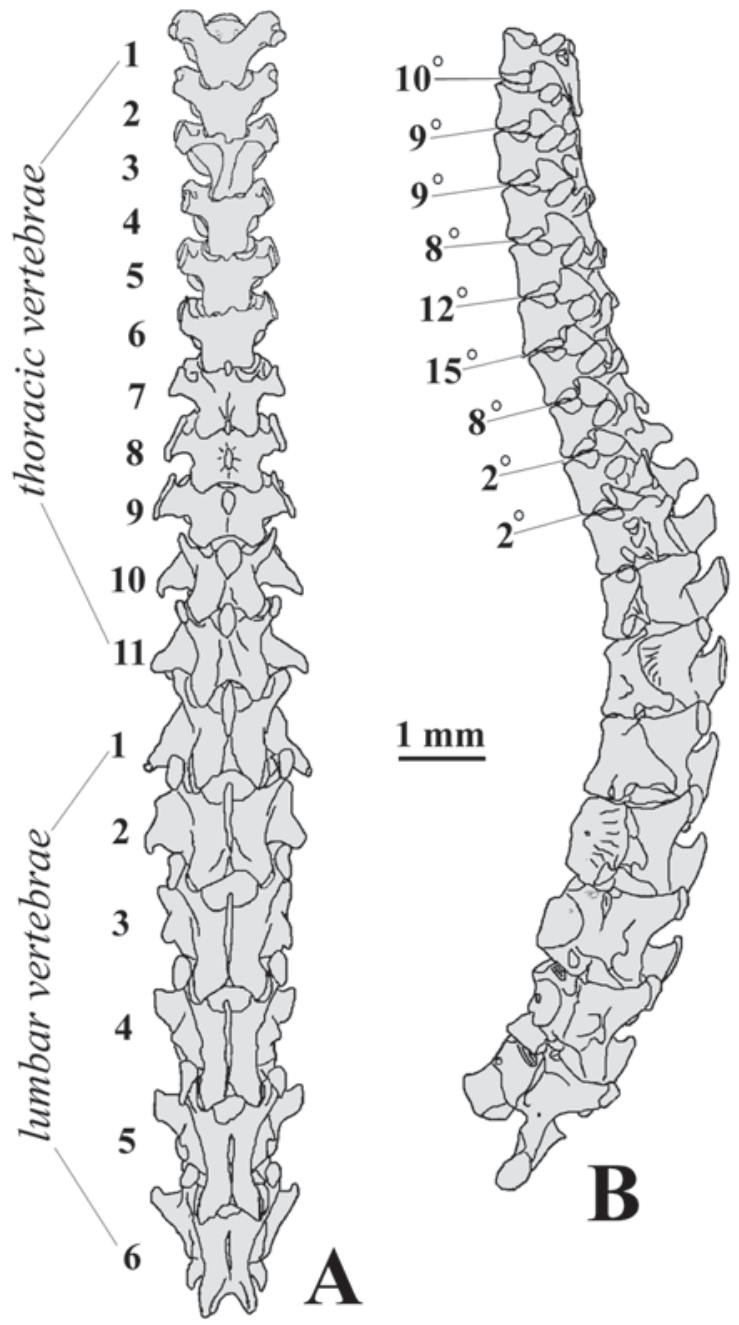

Figure 2. Thoracic and lumbaric regions in mole, Talpa europaea.

A - dorsal view. Figures denote the number of the vertebra; B lateral view. Figures denote maximum rotation angle between the two adjacent vertebrae.

\section{Results and discussion}

In mole the thoracic region consists of 11-14 vertebrae, the lumbar region always has six vertebrae. The shape of the vertebra centrum varies greatly in both thoracic and lumbar regions. Only the sixth thoracic vertebra has a typical for mammals platycoelous centrum. In thoracics 1, 8, and 9 the centrum is approaching the opisthocoelous condition, and in thoracics 3-5 it is of amphicoelous type. The second thoracic has a procoelous centrum, and the tenths thoracic combines amphicoelous and opisthocoelous morphology, having the anterior articulation surface flat and the posterior articulation surface strongly concave. The anterior articulation surface in thoracics 11 and 12 and in all lumbar vertebrae is inclined caudally; the posterior surface in these vertebrae is opisthocoelous. The ventral centrum surface in all thoracic and lumbar vertebrae is slightly 


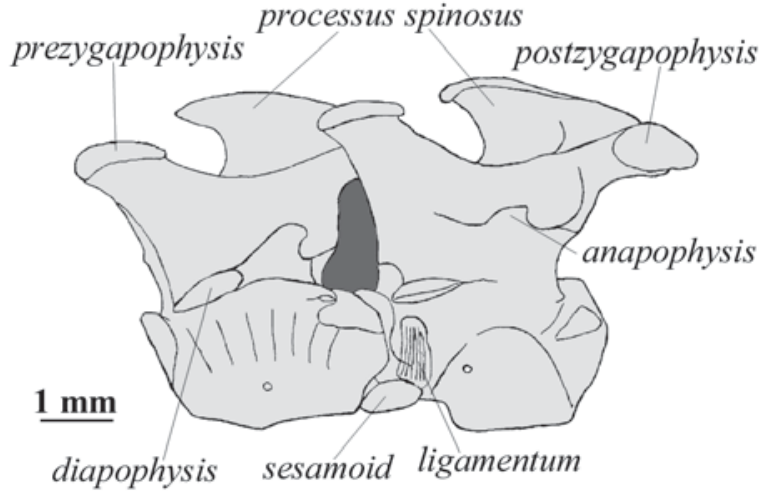

Figure 3. Third and fourth lumbar vertebrae in lateral view. The intervertebral foramen is black.

concave, except third and fourth lumbarics, which are convex ventrally (Fig. 2). Starting with 10-12 thoracics there are small sesamoid bones between the vertebral centra (Dobson, 1882), which are somewhat pressed into the centra and gradually increase in size caudally (Fig. 3). In thoracics at the base of neural arch cranially and caudally there are joint articulation surfaces for the rib head. The rib tubercle articulates the ventral surface of the diapophysis; this surface increases from first through seventh thoracics, decreases from eight through tenth thoracics, and disappears in last thoracics together with the diapophysis.

The neural arch is connected to the centrum by broad but thin peduncles, with weak anterior and more pronounced posterior incisura vertebralis. The latter decreases significantly from eleventh thoracics through fourth lumbarics and gradually increases in the following lumbarics. Incisurae vertebralis of adjacent vertebrae form the intervertebral foramen, through which the radixes of the spinal nerves comes out.

Above the diapophysis there is a metapophysis (processus mamillaris), which increases in size from first through ninth thoracics, reduces in size significantly on the tenth thoracic, and greatly increases on the eleventhtwelfth thoracics. The metapophysis does not changed significantly in size on lumbar vertebrae. In the secondninth thoracics the metapophysis is cranio-laterally projecting. From eleventh thoracic through sixth lumbaric it projects more dorsally, raising above the prezygapophysis, and fusing to the lateral surface of the latter.

The prezygapophyses are located close to the vertebra centrum in anterior thoracics, but gradually migrate cranially in more caudal vertebrae, partially protruding beyond the cranial margin of the centrum. The prezygapophyseal articulation surfaces are of oval shape in thoracics 1-3 and 8-12, and in all lumbarics. In thoracics 4-7 they are of round shape. Starting with the third thoracic the prezygapophyses could be recognized as distinct processes, directed cranially and dorsally. Staring with the second thoracic the prezygapophyseal articulation surfaces are bordered by a depression for inser-

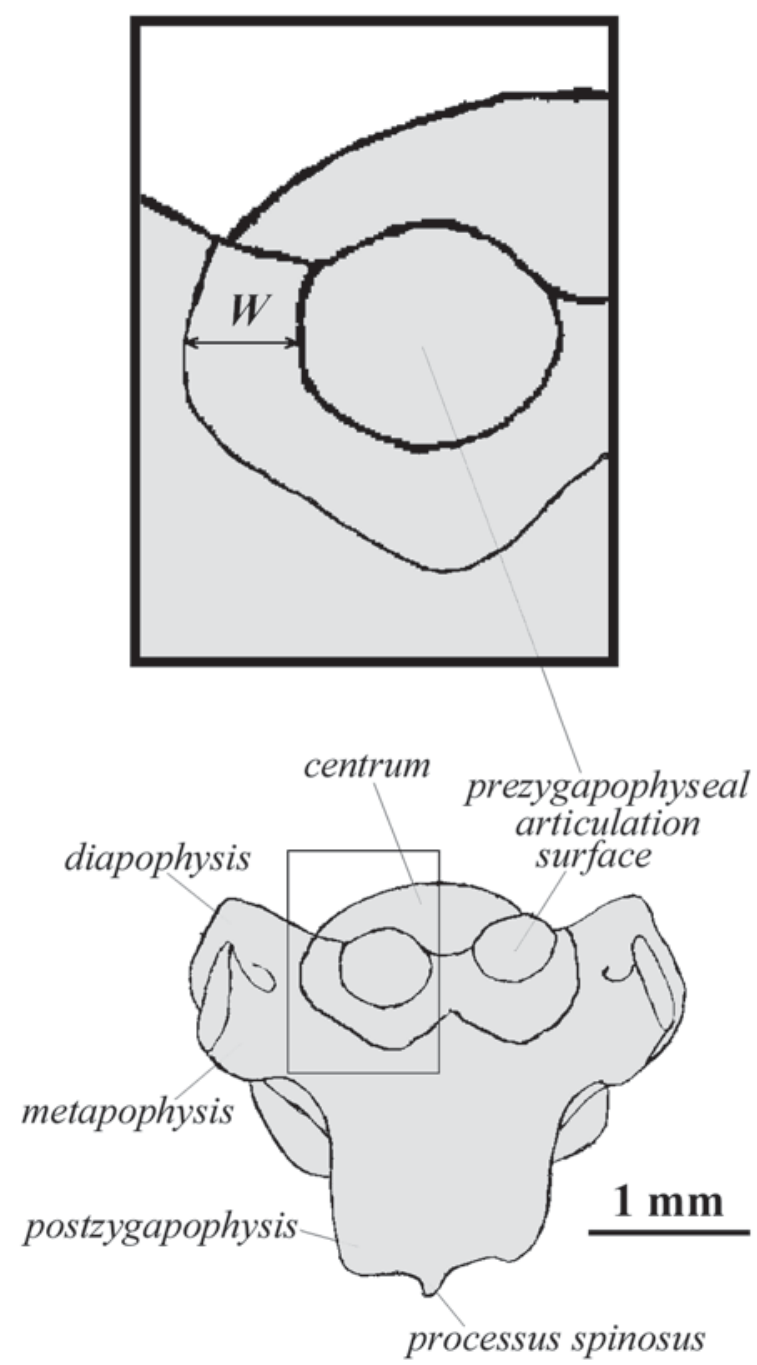

Figure 4. Third thoracic vertebra in dorsal view.

$W$ - a width of the lateral depression adjacent to the prezygapophyseal articulation surface, which allows an additional shift of the second thoracic relative the third thoracic.

tion of the articulation capsule (Fig. 4). This depression borders articulation surfaces laterally and caudally in the thoracics $2-6$, partially laterally and caudally in the seventh thoracic, and exclusively caudally in thoracics 8-12 and in all lumbarics. Between the prezygapophyses there is an incisura, which increases in size from fifth towards twelfth thoracics. The zygapophyseal articulation surfaces are convex dorsally in first-tenth thoracics, and since 10-11 thoracics it becomes concave ventrally.

The postzygapophyses are protruding caudally beyond the caudal margin of the vertebra centrum. The postzygapophyses are process-like in all vertebrae. The postzygapophyses are separated by an incisura, which increases in size caudally and thus displacing the processes more laterally. The spinous process wedges in this incusura in second to sixth thoracics. The spinous process is absent in the first thoracic and vestigial in the second-third thoracics. In second-seventh thoracics the 

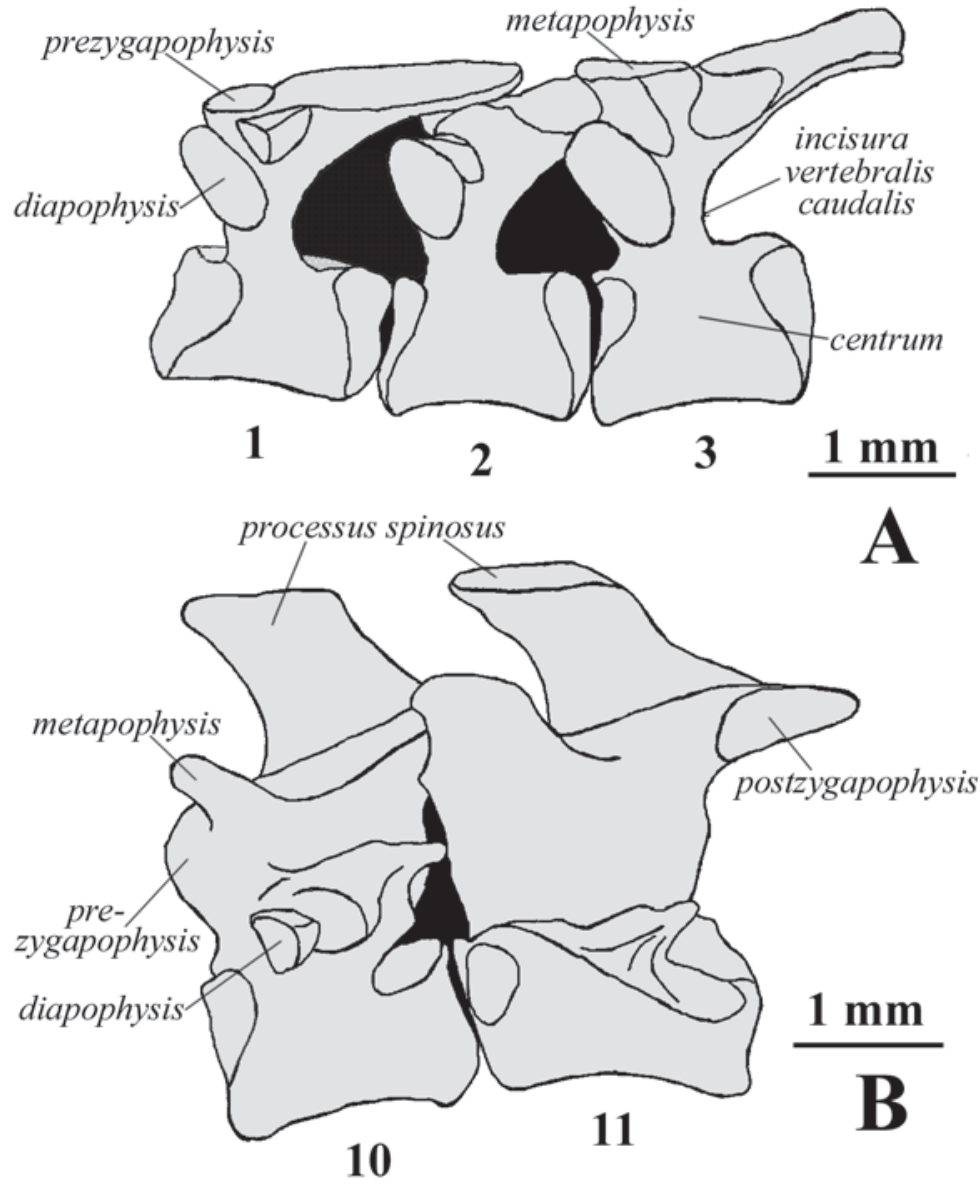

Figure 5. Thoracic vertebrae in lateral view.

A - Thoracics first to third. A relatively large intervertebral foramen (black area) allows a large rotational angle between two adjacent vertebrae without jam of the spinal nerves and vessels; B - Thoracics tenths to elevenths. A small size of the intervertebral foramen does not allow a considerable rotation between two adjacent vertebrae.

tension of this depression promotes the cranio-caudal movement in this articulation and provides the dorso-ventral flexure of two adjacent vertebrae. As this caudal depression is characteristic for all thoracic and lumbar vertebrae, all this vertebral section is liable to dorsoventral flexure.

The calculated angle of the vertebrae twist in mole is about $60-65^{\circ}$ for thoracics $1-9$, which is $7^{\circ}$ in average between the two adjacent vertebrae (Fig. $2)$. In more caudal vertebrae this angle drops to $2^{\circ}$ between the last thoracics. The rotation between the lumbar vertebrae does not exceed $0.5^{\circ}$ because their articulate surfaces do not form a common arch of the circle. In fact, the rotational angle of two adjacent vertebrae can be increased up to $80-90^{\circ}$ because of presence of lateral depressions lateral to the articulation surfaces, which can reach one third to one half width of the latter ( $W$ in Fig. 4). The calculated angle of rotation in the thoracic region of mole considerably exceeds that calculated for rat and zokor (maximum 15-18 $8^{\circ}$. Both of these animals do need rotation in the thoracic region, the former because it is not digger, the latter because it applies a different digging method. Zokor during digging keep both his fore and hind limbs in a parasagittal plane. Contrary, the mole has to turn the pectoral girdle up to $90^{\circ}$ to the horizontal plane on which the hind extremities are leaning (Hisaw, 1923; Skoczen, 1958; Gambaryan et al., 2003). So great rotation

spinal process projects on the caudal margin of the vertebra centrum. In the eighth thoracic this process lies between the prezygapophysis and postzygapophysis. In the ninth-tenth thoracics it projects on the incisura between the prezygapophyses. In the eleventh-twelfth thoracics and first lumbaric it projects beyond the cranial margin of the centrum. Starting with the second lumbaric the spinous process again inclines caudally.

Starting with the sixth thoracic vertebra the spinous process is widened in its dorsal portion; this round widening gradually increases in size caudally. In thoracics 9-12 this widening becomes a horizontal platform of oval shape. In lumbar vertebrae this widening is more narrow, strip-like; it increases in length in lumbarics 13 and decreases in lumbarics 4-6.

The shape of depression bordering the prezygapophyseal articulation surfaces suggest that the postzygapophiseal surfaces can get into this depression during vertebrae rotation. If so, the lateral extension of this depression relative to the prezygapophyseal articulation surface would indicate an increasing of the rotational angle between two adjacent vertebrae. The caudal ex- inevitability raises a question of the spinal nerves and vessels pinching during the vertebral column twisting. I have noticed, however, that the largest intervertebral foramens, formed mainly by a deep posterior vertebral incisura, occur in the parts of the vertebral column where the twisting process is the most intensive. This could be seen, for example, in the first three thoracic vertebrae (Fig. 5A). The foramen size allows the longitudinal twisting without disturbing the nerves and vessels. At the same time the foramen size is much smaller where the twisting process is minimal, for example, in tenth and eleventh thoracics (Fig. 5B).

One more question of mole digging style was addressed during this research, the possibility of throwing out the substrate by its head. Several authors (i.e., Folitarek, 1932; Stroganov, 1948; Formosov, 1952) assert that the mole throws the soil out by the head. Hisaw (1923) demonstrated, that the North American mole Scalopus aquaticus throw out the soil by the forelegs, not by the head. The same was observed for the common mole (Talpa europaea) using the cinefluorography method (Gambaryan et al., 2003). 
The interesting peculiarity was noticed in the comparative study of the thoracic and lumbar regions in some moles (Talpa, Mogera, Scalopus, and Condilura). All of these taxa have the similar dynamics of the spinous process size variation. It is vestigial or lacking in the first six-seven thoracics, from the eighth thoracics through the second lumbaric it is well developed, and then it is again decreasing in size until its almost complete reduction in the last lumbaric. As was shown recently by Gambaryan \& Gasc (1993), in animals actively using head during borrowing, the $\mathrm{mm}$. splenius and semispinalis capitis, responsible for the head and neck raising, are inserted on the spinous processes of the first three thoracic vertebrae. The spinous processes of the next three-four thoracics serve for insertion of the $\mathrm{m}$. semispinalis dorsi, producing the positive force vector for the head and neck lifting. The weak development of the spinous processes in the anterior thoracic vertebrae allow me to assert that the mole cannot use its head for the throwing away the substrate during digging. This is supported by the fact, that in zokor, which use its head for pushing away the soil, the most developed spinous processes are located exactly in the anterior thoracic region (Gambaryan \& Gass, 1993). Moreover, the skull in moles is very fragile and can not hold a strong pressure. In all the specialized diggers, which push out the soil by their head (Spalax, Myospalax, Chrysochloridae), the skull is considerably thickened to sustain the great pressure (Gambaryan \& Gasc, 1993).

The observations made above allow to reconstruct the following mode of the vertebral column movements during digging activity of the mole. In the solid substrate under the ground during the throwing soil out the rotation between the thoracic vertebrae is occurred at an angle up to $90^{\circ}$, and at the same time one fore leg is set against the tunnel's bottom while the other is pushing the soil out.

The distinctive swells on the ground surface, which could be seen on the trampled down forest paths, could be considered as result of such digging method.

\section{Conclusions}

1. The rotation along the longitudinal axis occurs mainly in the thoracic region of the mole's vertebral column. In this region the joints of the articulation capsule of the zygapophyses are shifted laterally from the articulation surfaces on the considerable distance.
Also the biggest intervertebral foramens, which prevent pinching the spinal nerves radixes while the vertebral column twist, occur in this region.

2 . The vertical bending may occur in both thoracic and lumbar regions, but it has a greater amplitude in the lumbar region. In this region the articulation capsules are fixed more caudal than the articulation zygapophyseal surfaces.

3. In mole the head is not used for throwing substrate out of the ground surface.

ACKNOWLEDGEMENTS. I am grateful to my supervisor Prof. P.P. Gambaryan for useful comments.

\section{References}

Dobson G.E. 1882. A Monograph of the Insectivora, Systematics and Anatomy. London: P.I. John Van Voorst. 172 p.

Folitarek S.U. 1932. [Distribution, biology, and industry of the mole in Ukraine] // Byulleten' Moskovskogo Obshchestva Ispytatelei Prirody. Novaya Seriya. T.41. No.3-4. P.235-302 [in Russian].

Formozov A.N. 1952. [Companion of a Pathfinder]. Moskva: Moskovskoe Obshchestvo Ispytatelei Prirody. 360 p. [in Russian].

Gambaryan P.P. 1960. [Adaptive Features of the Locomotory Organs in Fossorial Mammals]. Erevan: Izdatel'stvo AN Armyanskoi SSR. 195 p. [In Russian].

Gambaryan P.P. \& Gasc J.-P. 1993. Adaptive properties of the musculoskeletal system in the mole-rat Myospalax myospalax (Mammalia, Rodentia), cinefluorographical, anatomical, and biomechanical analyses of burrowing // Zoologiche Jahrbücher. Abteilung für Anatomie und Ontogenie der Thiere. Bd.123. Hf.4. P.363-401.

Gambaryan P.P., Gasc J.-P. \& Renous S. 2003. Cinefluorographical study of the burrowing movements in the common mole, Talpa europaea (Lipotyphla, Talpidae) // Russian Journal of Theriology. Vol.1 (for 2002). No.2. P.101-109.

Hisaw F.L. 1923. Observations on the burrowing habits of mole (Scalopus aquaticus mahrinoides) // Journal of Mammalogy. Vol.4. No.2. P.79-88.

Reed C.A. 1951. Locomotion and appendicular anatomy in three soricoid insectivores // American Midland Naturalist. Vol.45. No.3. P.513-671.

Skoczen S. 1958. Tunnel digging by the mole (Talpa europaea Linne) // Acta Theriologica. Vol.2. No.11. P.235-249.

Stroganov S.U. 1948. [Systematics of moles (Talpidae)] // Trudy Zoologicheskogo Instituta AN SSSR. T.8. No.2. P.1-405 [in Russian]. 